\title{
The challenge of developing a herpes simplex virus 2 vaccine
}

\author{
Lesia K Dropulic ${ }^{\star}$ and Jeffrey I Cohen \\ Medical Virology Section, Laboratory of Infectious Diseases, National Institute of Allergy \& \\ Infectious Diseases, National Institutes of Health, Bethesda, MD, USA
}

\begin{abstract}
HSV infections are prevalent worldwide. A vaccine to prevent genital herpes would have a significant impact on this disease. Several vaccines have shown promise in animal models; however, so far these have not been successful in human clinical studies. Prophylactic HSV vaccines to prevent HSV infection or disease have focused primarily on eliciting antibody responses. Potent antibody responses are needed to result in sufficiently high levels of virusspecific antibody in the genital tract. Therapeutic vaccines that reduce recurrences need to induce potent T-cell responses at the site of infection. With the increasing incidence of HSV-1 genital herpes, an effective herpes vaccine should protect against both HSV-1 and HSV-2. Novel HSV vaccines, such as replication-defective or attenuated viruses, have elicited humoral and cellular immune responses in preclinical studies. These vaccines and others hold promise in future clinical studies.
\end{abstract}

\section{Keywords}

animal models; genital herpes; herpes simplex virus; immune response; prophylactic vaccine; therapeutic vaccine

\section{Pathogenesis}

HSV-2 contains a double-stranded DNA genome of about $152 \mathrm{~kb}$ pairs that encodes at least 84 proteins. The viral genome is enclosed in an icosahedral capsid surrounded by an envelope composed of a lipid bilayer and at least 13 viral glycoproteins. Transmission of the virus requires intimate contact between a person excreting HSV and a susceptible person. The portal of entry for HSV-2 infection is the genital or, less frequently, oral mucosa or areas of abraded skin. The virus replicates in epithelial and mucosal cells with subsequent infection of sensory nerve endings. The virus is then transported to dorsal root or cranial nerve ganglia where latency is established. Primary genital infection results in painful vesicles and ulcers, and can be complicated by fever, local lymphadenopathy, dysuria, paresthesias and aseptic meningitis. HSV-2 can be spread to the neonate during delivery,

\footnotetext{
(C) 2012 Expert Reviews Ltd

*Author for correspondence: Tel.: +1 301496 7675, Fax: +1 301480 7321, dropulicl@niaid.nih.gov.

For reprint orders, please contact reprints@expert-reviews.com

Financial \& competing interests disclosure

This work was supported by the intramural research program of the National Institute of Allergy and Infectious Diseases at the NIH. One of the authors (JI Cohen) has a Cooperative Research and Development Agreement (CRADA) with Immune Design Corporation that provides funding to test a therapeutic HSV-2 vaccine in an animal model and both authors have a CRADA with Sanofi Pasteur which will provide funding to evaluate the HSV-2 dl5-29 vaccine in a clinical trial. The authors have no other relevant affiliations or financial involvement with any organization or entity with a financial interest in or financial conflict with the subject matter or materials discussed in the manuscript apart from those disclosed.

No writing assistance was utilized in the production of this manuscript.
} 
resulting in disseminated infection in the newborn. The virus can reactivate from latency to cause recurrent disease at mucosal and epithelial surfaces, resulting in genital herpes or herpes labialis; shedding from these sites can spread virus to susceptible contacts. The observation that HSV-2 frequently reactivates in the presence of virus-specific neutralizing antibody and T-cell responses implies that a therapeutic vaccine based on the development of the level of immune responses observed during natural infection might be insufficient to prevent disease associated with reactivation.

\section{Rationale for the development of an HSV-2 vaccine}

Worldwide, more than 500 million people are estimated to be infected with HSV-2 [1]. While genital herpes can cause substantial morbidity including psychological distress, the majority of persons infected with HSV-2 are asymptomatic and unaware of their recurrences [2]. Asymptomatic shedding facilitates the spread of HSV-2 throughout the population. Disseminated HSV-2 infection of neonates, which can result from exposure to HSV during delivery, has a mortality rate up to $85 \%$ if untreated [3]. Seventy five percent of these babies develop encephalitis and nearly all of them have significant neurological sequelae [4]. HSV-2 causes severe, sometimes refractory disease in patients with HIV/AIDS and other immunocompromising conditions $[5,6]$. In addition to severe genital and anal disease, HSV-2 can cause visceral disease and infect the spinal cord in patients with HIV/AIDS [7]. Epidemiologic studies have demonstrated that HSV-2 seropositive persons have a two- to fourfold increased risk of acquiring HIV-1 infection [8]. In addition, HSV increases the risk of HIV transmission if the source partner is infected with HSV-2 [8,9]. While antiviral drugs suppress recurrences of genital HSV disease and decrease shedding, they reduce HSV transmission rates to susceptible partners by only about $50 \%$ [10].

\section{Animal models used for HSV-2 vaccine development}

Animal models are critical for development of HSV-2 vaccines. The principal animals used are mice and guinea pigs, although cotton rats and owl monkeys have been used to a limited extent (Table 1). Most candidate HSV-2 vaccine studies are initially tested in mice. Mice infected vaginally with HSV-2, after treatment with medroxyprogesterone, develop acute disease, shed virus during acute infection, and establish latent infection in the associated dorsal root ganglia. Humoral and cellular immune responses to the vaccine can be measured easily. Spontaneous reactivation does not occur, but can be induced with UV irradiation or hyperthermia $[11,12]$. Therefore, in mice, it is not possible to evaluate the impact of vaccination on recurrent disease. In addition, intravaginal inoculation of virus often results in spread of the virus to the sacral ganglia resulting in urinary retention, hind limb paralysis, and death of the mouse. The use of inbred strains or HLA transgenic mice, allows one to determine the contribution of individual components of the immune system to control infection or to determine human T-cell epitopes, respectively.

Since guinea pigs experience spontaneous recurrences of genital herpes, they serve as a useful model for testing whether prophylactic vaccines prevent acute disease and recurrences, as well as whether therapeutic vaccines reduce recurrences in animals that were previously infected $[13,14]$. Guinea pigs shed virus during acute infection, have recurrences that are HSV-2 DNA PCR positive (less frequently HSV-2 culture positive) and develop latent infection of sacral ganglia after intravaginal infection. Antibody responses to the virus can be measured but cellular immunity has not been well characterized, owing to lack of immune reagents.

Intravaginal inoculation of cotton rats with HSV-2 results in acute infections that do not require prior treatment with medroxy-progesterone [15]. Spontaneous recurrences occur. 
Unfortunately, these animals are difficult to work with and, as with guinea pigs, reagents for measuring immunity are limited.

HSV-2 infection of rhesus macaques treated with medroxy-progesterone results in genital lesions in up to $10 \%$ of animals; thus, the rhesus model is not practical for vaccine studies [16]. By contrast, owl monkeys (Aotus trivirgatus) develop fatal infections after inoculation with HSV-2 [17]. These animals have been used to demonstrate the safety of live attenuated vaccines [18].

While candidate HSV-2 glycoprotein vaccines have been protective in mice and guinea pigs, these vaccines have all failed in human clinical trials. A number of reasons may explain these findings. First, HSV has coevolved with humans over millions of years, and major histocompatibility complex alleles are different in humans than in other animals. Viral proteins are likely to have changed their sequences to limit their recognition by the human immune system, which is different from the murine immune system, especially innate and mucosal immunity. In addition, the distribution of types of immune cells in the genital mucosa of inbred mice differs from that of outbred human populations. Second, the virus encodes a number of immune evasion genes. Many of these have species-specific effects. For example, HSV ICP47, which downregulates MHC class I by inhibiting TAP, has significantly less activity in mouse than in human cells [19]. Glycoprotein E binds the Fc domain of human IgG and blocks its activity, but does not bind the Fc domain of mouse or guinea pig IgG [20]. Third, animals are usually given a single challenge dose, while humans are challenged with virus during multiple exposures. While this reduces the required number of animals to show effectiveness of vaccines and improves statistical power, it differs markedly from human infection, in which most exposures to HSV-2 do not result in clinical disease. As such, vaccines that are ineffective in animals owing to an overwhelming titer of challenge virus might be effective in humans. Fourth, animals are usually challenged at the peak of their immune response to a vaccine, while humans would become infected months to years after vaccination. Fifth, viruses used to challenge animals are usually amplified in cell culture where they may undergo attenuating mutations [21]. Humans are infected with viruses that have not been passaged in culture.

\section{Viral proteins as immunogens}

\section{Neutralizing antibodies}

HSV contains 13 glycoproteins in its envelope that function in virus attachment, entry and fusion with cells. The most abundantly expressed glycoprotein on the virion and on the surface of virus-infected cells is glycoprotein $\mathrm{D}(\mathrm{gD})$. $\mathrm{gD}$ is a major target of neutralizing antibodies [22]. HSV-2 $\mathrm{gD}$ shares $98-99 \%$ amino acid identity among different HSV-2 strains and $82-88 \%$ amino acid identity with $\mathrm{gD}$ of different HSV-1 strains. $\mathrm{gD}$ is also a target of antibody-dependent cellular cytotoxicity, as well as of $\mathrm{CD}^{+}{ }^{+}$and $\mathrm{CD} 8^{+} \mathrm{T}$-cell responses [23,24]. Glycoproteins $\mathrm{gB}, \mathrm{gC}$ and $\mathrm{gE}$ also trigger humoral and cellular immune responses. HSV-specific antibody is important for preventing neonatal HSV-2 disease [25]. Women who were previously infected before childbirth transmit HSV antibody across the placenta and are less likely to have infants with neonatal HSV-2 disease than women with acute HSV-2 infection at the time of childbirth, before antibody can be transmitted to the neonate [26]. A gD subunit vaccine that induced antibody to glycoprotein $\mathrm{D}$ at titers greater than those achieved with natural infection did not protect humans from HSV-2 genital disease [27]. This glycoprotein subunit vaccine may have been inadequate because the elicited immune responses were limited to a few epitopes, the duration of the neutralizing antibody response was very transient and the vaccine did not induce virus-specific CD8 ${ }^{+} \mathrm{T}$ cells [28]. 


\section{T-cell responses}

Activated $\mathrm{CD} 4^{+} \mathrm{T}$ cells are present early in HSV lesions in humans and later $\mathrm{CD} 8^{+} \mathrm{T}$ cells traffic to lesions [29,30]. $\mathrm{CD} 8^{+} \mathrm{T}$ cells persist in lesions more than 2 months after lesions heal, and are associated with clearance of virus [30,31]. In mice, the rate of reactivation is dependent upon the number of infiltrating $\mathrm{CD} 8^{+} \mathrm{T}$ cells and the number of viral genomes in latently infected ganglia $[31,32] . \mathrm{CD}^{+} \mathrm{T}$ cells are associated with clearance of virus and control reactivation in ganglia of mice $[32,33]$.

HSV-2-specific CD8 ${ }^{+} \mathrm{T}$ cells recognize a large array of HSV proteins. In a study of 48 viral proteins in $21 \mathrm{HSV}-2$ seropositive subjects, the most frequent proteins recognized by $\mathrm{CD} 8^{+}$ T cells (in order from highest to lowest) were UL39 (the viral large subunit of ribonucleotide reductase), UL25 capsid protein, UL27 (gB), ICP0 (an immediate-early protein), UL46 tegument protein, UL47 tegument protein, UL19 capsid protein, UL36 tegument protein, UL49 tegument protein and UL26 tegument protein [34]. HSV-2 infected persons recognized between three and 46 of 48 viral proteins, with a median of 11 proteins per person. A second study evaluated 14 viral proteins in $55 \mathrm{HSV}-2$ seropositive persons and found that the most frequently recognized HSV-2 proteins were UL39, ICP0, UL49, UL19, UL25, UL46, UL27, UL47, UL29 (single-stranded DNA binding protein), ICP27 (an immediate-early protein), UL11 tegument protein, UL35 capsid protein and US6 (gD) [35]. The HSV-2 specific CD8 ${ }^{+}$T cells more often expressed IFN- $\gamma$ than IL-2 or TNF- $a$, and more often expressed granzyme $\mathrm{B}$ than perforin. When $\mathrm{CD} 8^{+} \mathrm{T}$ cells were sorted for cells expressing the cutaneous lymphocyte-associated antigen (a skin homing associated receptor), a more limited number of viral proteins were recognized [36]. Analysis of HSV-2specific $\mathrm{CD}^{+} \mathrm{T}$ cells from genital lesions showed that UL47, UL49 and ICP0 were recognized by the cells [37], while virus-specific $\mathrm{CD}^{+} \mathrm{T}$ cells from genital lesions recognized UL49, UL50 (the viral dUTPase) and the UL21 tegument protein [38].

A study comparing T-cell responses present in the blood of HSV-2 immune but seronegative persons with HSV-2 seropositive persons showed that the former had T cells predominantly directed against UL39 (55\% of persons responding), and the immediate-early proteins ICP4 (35\%) and ICP0 (25\%), followed by UL19 (15\%) and UL29 (15\%). By contrast, HSV-2 seropositive persons had T-cell responses to UL39 (50\%), gD (43\%), ICP0 (40\%), ICP4 (38\%), UL46 (25\%), UL49 (28\%) and gB (20\%) [39]. This suggests that T-cell responses to UL39 and immediate-early proteins (rather than glycoprotein or tegument proteins) might be more important to protect against HSV-2 infection.

Innate immune responses are also important for control of HSV-2. IFN- $\alpha$ and IFN- $\beta$ inhibit HSV replication [40,41]. Mutations in UNC-93B (UNC-93 homolog B1), TLR3, TRAF3 and TRIF are associated with childhood herpes simplex encephalitis [42]. Patients with mutations in STAT1, Tyk2, TR AF3, NEMO, as well as those with NK cell deficiency, have been reported with severe HSV infections [43].

At present, it is not known which immune responses are required to protect against HSV-2 disease. The observation that persons can be infected with more than one strain of HSV-2 suggests that vaccines may not completely protect against infection $[44,45]$. However, it is possible that these persons were initially infected with multiple strains rather than sequentially infected with different strains. Vaccines may protect against disease, reduce virus shedding or reduce the level of infection such that rates of transmission, neonatal disease and other symptomatic diseases are reduced. 


\title{
History of HSV-2 vaccines tested in clinical studies
}

\section{Early studies with inactivated virus \& virus components from inactivated virus-infected cells}

\begin{abstract}
Attempts at developing an HSV vaccine date back to the 1930s. The vaccines were evaluated either as prophylactic or therapeutic vaccines. Prophylactic vaccines prevent acquisition of HSV-2 infection and/or prevent clinical disease, whereas therapeutic vaccines minimize disease severity and/or prevent HSV recurrences in persons who are already infected. Early research was hampered by crude vaccine preparations and poorly designed clinical studies. From the 1940s to the 1960s, vaccine virus was grown in embryonated eggs and later in cell cultures, and inactivated by UV irradiation, heat or chemicals. The first randomized, double-blind, placebo-controlled clinical trial of an HSV vaccine was conducted by Kern and Schiff in 1964 [46]. Formaldehyde-inactivated whole virus vaccine was administered to patients with recurrent HSV. The decrease in the number of recurrences was similar between the vaccine and placebo recipients. Other inactivated HSV vaccines have been tested in humans; however, they were not tested in double-blind, placebocontrolled trials and, therefore, the efficacy of the vaccines cannot be determined.
\end{abstract}

Owing to difficulties in ensuring that the entire virus is inactivated, vaccine developers isolated HSV components from detergent extracts of inactivated virus-infected cells. One such vaccine composed of DNA-free viral antigens extracted from HSV-infected human cells was tested in a double-blind study of 42 subjects experiencing frequent recurrences of HSV-1 or HSV-2 disease [47]. This vaccine was highly immunogenic in laboratory animals; however, it was poorly immunogenic in vaccinated subjects and there was no significant difference in reduction of clinical disease between the control and vaccine recipients.

In 1990, Mertz et al. reported the results of a double-blind, placebo-controlled trial of a vaccine containing $\mathrm{HSV}-2 \mathrm{gB}, \mathrm{gC}, \mathrm{gD}, \mathrm{gE}$ and $\mathrm{gG}$ derived from virus-infected chick embryo fibroblasts [48]. The vaccine failed to protect HSV-2 seronegative recipients, whose partners had documented recurrent genital herpes, from developing HSV-2 genital disease. Antibody titers to HSV-2 gD and gB were very low compared with the partners with recurrent genital herpes.

Skinner et al. developed a cell culture-derived vaccine composed of a mixture of HSV-1 glycoproteins inactivated with formalin and extracted with detergents [49]. A multicenter, placebo-controlled trial of this vaccine in patients with frequently recurring genital herpes revealed that the vaccine did not significantly decrease the frequency of genital herpes recurrences in women at 3 and 6 months after vaccination [49]. However, the severity of recurrences was significantly decreased as defined by a reduced number of lesions and reduced symptoms per recurrence. The vaccine induced both neutralizing antibody and cellular immunity to HSV-1.

\section{Prophylactic vaccines}

\section{Recombinant glycoprotein subunit vaccines}

Glycoprotein vaccines consist of one or more glycoproteins combined with adjuvants that boost their immunity. gD2/gB2-MF59 is a subunit vaccine composed of truncated gD2 and gB2 with M59 adjuvant, an oil-in-water emulsion that includes squalene. This vaccine was evaluated in two randomized, double-blind, placebo-controlled studies. The first included 531 HSV-2 seronegative partners of HSV-2-infected persons, and the second study included 1862 individuals attending a sexually transmitted diseases clinic and at high risk of HSV-2 infection (Table 2) [50]. For the initial 5 months after vaccination, the acquisition rate of HSV-2 infection was 50\% lower in vaccine recipients. However, the vaccine was not 
successful in preventing infection after 1 year of follow-up and there was no effect on the rate of symptomatic HSV-2 infection, despite inducing neutralizing antibody levels exceeding those induced by natural infection. These results suggest that neutralizing antibodies alone may not be sufficient to protect against genital HSV-2 infection. Preexisting immunity to HSV-1 did not influence the rate of acquisition of HSV-2 but did increase the proportion of asymptomatic infections.

The gD2-Alum monophosphoryl lipid A (MPL) vaccine is composed of gD2 combined with aluminum hydroxide (alum) and 3-O-deacylated MPL. Two trials were performed and the results reported together [51]. The first trial studied HSV-1 and HSV-2 seronegative partners of persons with a history of genital herpes and showed only $38 \%$ vaccine efficacy to prevent genital disease (HSV-1 or HSV-2). The second trial evaluated female partners (regardless of their HSV serostatus) of persons with a history of genital herpes and also showed no significant protection from genital disease ( $42 \%$ efficacy). However, subgroup analyses demonstrated that this gD2 subunit vaccine was protective (73 and 74\% efficacy, study 1 and study 2, respectively) against HSV genital disease in HSV-1 and HSV-2 seronegative women, but not in HSV-1 seropositive/HSV-2 seronegative women or in men, regardless of their HSV serostatus.

The results of the initial two gD2 alum/MPL vaccine studies led to the evaluation of this vaccine in a larger vaccine trial (HerpeVac Trial for women) of $8323 \mathrm{HSV}-1$ and HSV-2 seronegative women [28]. Surprisingly, the vaccine was not effective in preventing genital herpes disease (the primary endpoint) or infection. However, a substudy analysis showed that the vaccine was partially effective in preventing genital infection (35\% reduction) and disease (58\% reduction) caused by HSV-1. Antibody to HSV correlated with protection from HSV-1 infection. The discordant results of the initial gD2 alum/MPL studies and the Herpevac study are not fully explained; however, the former studies involved women whose 'regular sexual partners' had clinically confirmed genital herpes, while the latter study involved women who were at risk of HSV infection and disease. Interestingly, HSV-1 was a more common cause of genital herpes than HSV-2 in the control group of the Herpevac trial, which emphasizes the importance of a herpes vaccine that can protect against both HSV-1 and HSV-2. The vaccine induced both antibody and $\mathrm{CD} 4^{+} \mathrm{T}$ cells that recognized gD2; thus, the results suggest that these immune responses are insufficient to prevent genital herpes infection and disease.

\section{Attenuated live virus vaccines}

Attenuated live virus vaccines should present a broader array of HSV antigens than subunit vaccines, and therefore would be more likely to induce virus-specific $\mathrm{CD} 8^{+} \mathrm{T}$-cell responses than subunit vaccines. R7020 is an attenuated live HSV-1 vaccine that has a 700 bp deletion in the thymidine kinase gene and a $14 \mathrm{kbp}$ deletion into which are inserted several glycoproteins of HSV-2 [52]. R7020 established latency at a reduced rate in mice, guinea pigs and rabbit models compared with wild-type virus and protected animals against 'severe infections' after challenge with wild-type virus [52]. In clinical studies, the vaccine was poorly immunogenic at the maximum dose tested $\left(10^{5} \mathrm{pfu}\right)[53]$.

\section{Therapeutic vaccines}

\section{Recombinant glycoprotein subunit vaccines}

Straus et al. studied two glycoprotein subunit vaccines in patients with frequently recurrent genital herpes to test the feasibility of modifying an established HSV infection (Table 3) $[54,55]$. The primary end point of the trials was the frequency of symptomatic outbreaks of genital herpes. In the first trial, recipients of a recombinant $\mathrm{gD} 2$ vaccine with alum experienced significantly fewer virologically confirmed recurrences per month [54]. In the 
second trial, in which subjects received a recombinant gD2/gB2 vaccine in MF59 adjuvant, the monthly rate of recurrences was not significantly reduced [55]. However, the duration of new lesion formation, symptoms and time to healing for the first recurrence after vaccination were significantly shortened. The investigators attributed the difference in outcomes of the two studies to the difference in amount of glycoproteins $(100 \mu \mathrm{ggD} 2$ vs 10 $\mu \mathrm{g}$ each of $\mathrm{gB} 2$ and $\mathrm{gD} 2$ ) and the different adjuvants (alum vs MF59) used in the vaccines. They concluded that their studies support the concept of a therapeutic vaccine for ameliorating recurrences of HSV-2.

\section{Live virus vaccines}

Casonova et al. created a live virus vaccine, ICP $10 \Delta \mathrm{PK}$, in which the protein kinase domain of the large subunit of ribonucleotide reductase was deleted [56]. The virus is impaired in its ability to establish latency in dorsal root ganglia and to reactivate from latency. In animal models, ICP10 $\triangle \mathrm{PK}$ elicited virus-specific $\mathrm{CD} 8^{+}$cytotoxic $\mathrm{T}$ cells. In cutaneous and vaginal animal models, vaccination with ICP10 1 PK prevented nearly $90 \%$ of recurrences [57]. In a small placebo-controlled, double-blind study of 32 patients with frequently recurring HSV genital disease, ICP10 $\triangle$ PK prevented recurrent HSV-2 genital disease in $37.5 \%$ of vaccine recipients from 10 to 180 days after the last vaccine dose $(p=0.068)$ [56]. Vaccinated patients had fewer recurrences (1.58) than placebo recipients $(3.13 ; \mathrm{p}=0.028)$. While these results are promising, recurrences were not documented virologically.

The only replication-defective therapeutic vaccine evaluated in a multicenter, randomized, controlled clinical trial in persons with frequently recurrent genital herpes was the disabled infectious single cycle $\mathrm{gH}$ deleted vaccine [58]. The recombinant vaccine virus was propagated in complementing cells that express the $H S V-2 g H g e n e$. The virus can infect cells but only undergoes a single cycle of replication in vivo, since normal human cells do not express $\mathrm{gH}$. The vaccine had no effect on reducing the time to first recurrence of genital herpes after vaccination (the primary end point), clinical disease or genital shedding.

\section{HSV-2 vaccines in early-stage clinical trials}

Investigators are applying novel molecular approaches to HSV-2 vaccine development. For example, Cattamanchi et al. tested a DNA vaccine consisting of a plasmid expressing gD2 in a Phase I, double-blind, controlled, dose-escalation, safety and immunogenicity trial [59]. gD2-specific cytotoxic T lymphocytes and lymphoproliferation responses were detected in one out of four subjects who received the highest dose of vaccine. Therefore, higher doses of vaccine or adjuvants will likely be required to generate an immune response.

Koelle et al. tested a vaccine (HerpV) consisting of recombinant heat shock protein (rhHsc70), an array of HSV-2 peptides (32 synthetic 35 mers predicted to contain HSV-2specific T-cell epitopes) and a saponin adjuvant [60]. Heat shock proteins have previously been shown to elicit T-cell responses against peptides that they chaperone [61]. The seven participants who had evaluable samples and who received the vaccine had statistically significant $\mathrm{CD}^{+}{ }^{+} \mathrm{T}$-cell responses to HSV-2 proteins and most of these subjects also had significant $\mathrm{CD}^{+} \mathrm{T}$-cell responses.

HSV immune evasion genes are important for virus manipulation of the immune system. The smallpox vaccine (vaccinia virus) is lacking a large number of immune evasion genes that contribute to its attenuation. A candidate HSV vaccine, ImmunoVEX ${ }^{\mathrm{HSV} 2}$ deleted for several immune evasion genes is currently in an early phase clinical trial in the UK [101]. 


\section{Vaccine approaches for the future}

\section{Recombinant glycoprotein subunit vaccines}

While gD in alum/MPL failed to protect HSV-1 seronegative women from HSV-2 disease [28], combining other HSV-2 glycoproteins with gD would provide additional immunogens and potentially block the ability of the virus to evade immune responses (Table 4). HSV-2 $\mathrm{gC}$ binds the $\mathrm{C} 3 \mathrm{~b}$ component of complement and inhibits complement-mediated neutralization of the virus [62]; therefore, antibodies to $\mathrm{gC} 2$ could block the ability of the virus to evade neutralization by complement. Immunization of mice with combined $\mathrm{gC} 2$ and gD2 in CpG and alum increased neutralizing antibody in the presence of complement, and reduced the amount of virus in ganglia after intravaginal challenge compared with animals that received gD2 alone; however, acute disease scores were not significantly better than for animals receiving $\mathrm{gD} 2$ alone [63]. Vaccination of guinea pigs with combined $\mathrm{gC} 2$ and $\mathrm{gD} 2$ in $\mathrm{CpG}$ and alum resulted in higher neutralizing antibody titers in the presence of complement, and fewer days of HSV-2 shedding during recurrent infection after challenge compared with animals vaccinated with gD2 alone; however, acute disease, vaginal shedding during acute disease and the frequency of recurrent genital disease after challenge was not reduced compared with animals receiving gD2 alone [63]. These studies suggest that in some settings adding other viral proteins may improve the vaccine's ability to protect against HSV-2 disease.

\section{Inactivated vaccines}

While inactivated HSV-2 has not been shown to be protective in humans, these vaccines were not given with newer adjuvants. A recent study compared four vaccines in the guinea pig genital model: empty plasmid vector followed by formalin-inactivated HSV-2 in alum/ MPL; vaccination with plasmids that express gD, UL5 and UL30 followed by formalininactivated HSV-2 in alum/MPL; vaccination with plasmids that express gD, UL29 and UL52 followed by formalin-inactivated HSV-2 in alum/MPL; or one dose of gD protein in alum/MPL [64]. All four vaccines showed similar levels of protection against acute disease, virus shedding and recurrence rates of genital herpes in guinea pigs. The three vaccines containing inactivated HSV-2 (but not the gD vaccine) significantly reduced the latent virus load compared with control. Thus, an inactivated HSV-2 in an effective adjuvant is another approach that should be considered in addition to replication-defective or live attenuated vaccines.

\section{Replication-defective vaccines}

Vaccine HSV-2 dI5-29 is deleted for two viral genes (UL5 and UL29) that are essential for virus replication and is grown in complementing cells that express these two proteins [65]. HSV-2 dI5-29 is impaired for latency in mice [66] and guinea pigs [67]. Repeated immunization of mice subcutaneously with HSV-2 d15-29 reduced acute virus shedding, vaginal lesions and mortality. HSV-2 $d 15-29$ also decreased latent infection after intranasal challenge with wild-type virus HSV-2 [66]. Vaccination of guinea pigs with HSV-2 dI5-29 reduced acute, recurrent and latent infection as well as shedding after challenge with wildtype virus when compared with unvaccinated animals [67]. Guinea pigs vaccinated with HSV-2 dI5-29 had higher neutralizing antibody titers and lower rates of vaginal shedding, and lower levels of HSV-2 DNA in the ganglia after challenge than animals vaccinated with HSV-2 gD [68]. Prior infection with HSV-1 did not diminish the effectiveness of HSV-2 $d 15-29$ vaccine to reduce acute and recurrent disease after challenge with HSV-2 in guinea pigs when compared with unvaccinated animals. HSV-2 d/5-29 was >250,000-fold less virulent than wild-type HSV-2 after intracranial inoculation [69]. 
CJ9-gD is replication-defective HSV-1 vaccine that is engineered to express increased levels of HSV-1 gD very early in infection [70]. The virus has a dominant negative mutation in UL9, which results in inability to replicate both its own viral DNA as well as that of wildtype virus in cells infected with the vaccine strain. Vaccination of mice with CJ9-gD reduced shedding, genital lesions, hind limb paralysis and death after intravaginal challenge with HSV-2 [71]. Vaccination of guinea pigs with CJ9-gD protected the animals from acute genital lesions and hindlimb paralysis, reduced virus shedding, prevented recurrent disease and reduced latent viral DNA after challenge with wild-type HSV-2 [72].

A third promising replication-defective HSV vaccine in development was created by deletion of UL29 and expressing the costimulation molecule, B7, in an attempt to enhance the T-cell immune response in a replication-defective vaccine [73]. Immunization of mice with this vaccine increased the number of IFN- $\boldsymbol{\gamma}$-producing T cells and reduced challenge virus replication in the vaginal mucosa, and neurologic and genital disease, and mortality compared with vaccination with replication-defective virus not expressing B7 [74].

\section{Live attenuated vaccines}

The only licensed human herpes virus vaccines are the live attenuated varicella vaccine to prevent chickenpox and the zoster vaccine to prevent shingles. Attenuated herpes virus vaccines are used to prevent a number of veterinary herpes viruses including pseudo-rabies virus, Marek's disease and bovine herpesvirus 1 . Thus, a live attenuated vaccine may be more likely to be effective than a subunit vaccine; however, safety issues are paramount, especially if the vaccine virus can establish latency.

HSV-2 gE is critical for cell-to-cell spread in vitro, including from epithelial cells to axons, from neurons to epithelial cells, and for anterograde transport from neuron cell bodies to axons [75]. An HSV-2 gE deletion mutant was more than 100,000-fold less virulent in mice than wild-type virus after intracerebral inoculation, and caused no death or disease after infection of BALB/c and SCID mice when administered intramuscularly or intravenously [76]. The HSV-2gE deletion mutant had a greater than 100-fold or greater than 100,000-fold higher 50\% lethal dose in SCID mice than wild-type virus after intramuscular or intravaginal inoculation, respectively [75]. Two prophylactic immunizations of guinea pigs with the HSV-2 gE mutant resulted in reduced acute vaginal shedding and disease, and reduced recurrent vaginal shedding and lesions compared with control cell lysate after challenge with HSV-2 [76]. Therapeutic immunization of guinea pigs previously infected with HSV-2 reduced the incidence of recurrent genital disease.

HSV ICP0 is an immediate-early protein that functions as an interferon antagonist in both HSV-1 [77] and HSV-2 [78]. Intraocular vaccination of mice with an HSV-2 mutant deleted for the nuclear localization signal of ICP0 (HSV-2 $0 \Delta \mathrm{NLS}$ ) protected the animals from lethal intraocular infection after challenge of the contralateral eye with wild-type HSV-2 [78]. Vaccination of mice with HSV-2 $0 \Delta$ NLS was superior to vaccination with HSV-2 gD in alum/MPL in reducing vaginal shedding and mortality after intravaginal challenge with HSV-2 [79]. HSV-2 $0 \Delta$ NLS induced higher levels of neutralizing antibody than gD in alum/ MPL. However, the majority of severely immunocompromised mice inoculated with HSV-2 $0 \triangle \mathrm{NLS}$ died from vaccination; thus, the vaccine is likely not sufficiently attenuated for general use [78].

HSV-2 gD binds to several receptors, principally nectin-1, on epithelial cells and neurons, and to herpes virus entry mediator (HVEM) on epithelial cells and lymphocytes. HSV-1 pseudotyped to carry gD mutations showed that amino acid substitutions at amino acids 215 , 222 and 223 of gD reduced binding to nectin-1 and impaired nectin-1-mediated entry of virus into cells; however, the mutations did not inhibit binding to HVEM or entry into cells 
expressing HVEM [80]. These studies suggested that HSV with gD mutants that impair entry via nectin-1 might be used as vaccine candidates in that they would replicate in epithelial cells in the periphery, but not infect neurons. Based in part on these findings, an HSV-1 candidate vaccine was constructed with a mutation at amino acid $3 \mathrm{~g} g \mathrm{gD}$; the mutant was impaired for entry into nectin-1 as well as HVEM expressing cells [81]. The mutant was attenuated, and protected mice from acute and recurrent disease and death after challenge with HSV-1 inoculated into the flank. An HSV-2 candidate vaccine with mutations at amino acids 215,222 and 223 in $\mathrm{gD}$ infected human epithelial cells but was severely impaired for infecting neuronal cells [82]. When inoculated into mice, the vaccine was safe and protected against challenge with a lethal dose of wild-type HSV-2 [Wang et al, Unpublished Data].

\section{Expert commentary}

While the ultimate goal of any vaccine is to induce sterilizing immunity, a more practical goal for an HSV-2 vaccine would be to reduce disease and genital shedding. The only licensed herpes virus vaccine that reduces disease due to primary infection is the varicella vaccine, which diminishes disease associated with varicella, but does not induce sterilizing immunity [83]. In addition, the observation that persons can be infected with more than one strain of HSV-2 implies that sterilizing immunity might not be possible [44]. An HSV-2 vaccine that protects the recipient from primary disease and reduces reactivation and shedding, even without inducing sterilizing immunity, would reduce transmission of virus and potentially alter the epidemiology of HSV-2 infection. Such a vaccine would be a major contribution to public health.

Therapeutic vaccine studies in humans, in which the 'attack rate' or frequency of recurrences is high can be performed with far fewer subjects than prophylactic vaccine studies in which the 'attack rate' is usually $55 \%$. Thus, there is a preference to perform therapeutic vaccination Phase III trials with HSV-2 vaccines. In our opinion, however, it will be more difficult to achieve success in a therapeutic vaccine trial, as the vaccine would need to induce a more effective immune response than is naturally produced in a person with frequent virus reactivation [84]. Therefore, it is possible that a failed therapeutic vaccine might be fully successful if it is tested as a prophylactic vaccine [58].

In our opinion, efforts should focus primarily on the development of prophylactic vaccines until more is understood about the biology and immunology of reactivation. While numerous virus vaccines are approved to prevent disease associated with primary infection, only the herpes zoster vaccine is licensed to prevent reactivation of a virus infection.

Importantly, varicella-zoster virus, which causes shingles, is thought to reactivate only once in most persons, while HSV-2 reactivates on nearly a daily basis [85]. Therefore, while the zoster vaccine is an important precedent for a therapeutic HSV-2 vaccine, the pathophysiology of varicella-zoster virus and HSV-2 reactivation are very different.

Glycoprotein vaccines are likely to be extremely safe and induce high levels of neutralizing antibody; however, they are unlikely to be effective as both a prophylactic and therapeutic vaccine. The observation that an HSV-2 gD vaccine induced antibodies at levels higher than those observed in healthy seropositive persons and did not protect humans from HSV-2 disease [27] suggests that $\mathrm{gD}$ alone may be insufficient or that more immunogenic methods are needed to deliver $\mathrm{gD}$. A vaccine that induces both potent antibody and T-cell responses will likely protect against primary disease, as well as reduce reactivation in those who eventually become infected, since cellular immunity is important for control of virus reactivation. The only licensed vaccine that protects against primary infection with a human herpes virus is the live attenuated varicella vaccine, which induces both potent humoral and cellular immunity. This suggests that a live attenuated HSV-2 vaccine would most likely be 
successful, if it is sufficiently safe. An alternative and safer approach would be a replicationdefective HSV-2 vaccine, assuming it could be sufficiently immunogenic. Such a vaccine could be either a disabled infectious single cyle vaccine that can infect cells and release noninfectious virus or a replication-incompetent vaccine that infects cells, but does not produce virus [86].

The correlates of protection for a prophylactic HSV-2 vaccine are unknown at present. The only licensed viral vaccine that prevents a genital infection is the human papillomavirus vaccine. This vaccine induces antibody titers that are approximately tenfold higher than those seen with natural infection [87]. These high titers might enable the antibodies to reach the mucosal surface as a transudate, which may result in protection from infection [88]. It is important to note, however, that HPV and HSV are very different viruses and that they bind to different cell types. The initial target of HPV during primary infection is the cervicovaginal basement membrane followed by infection of basal epithelial cells [89]. HSV targets mucosal epithelial cells directly. Nonetheless, this suggests that humoral responses to HSV, sufficient to result in high levels of antibody in the genital tract, might result in protection from HSV disease and/or infection.

\section{Five-year view}

Since the gD2 Herpevac vaccine did not demonstrate significant efficacy against overall genital herpes disease in HSV-1 and HSV-2 seronegative women, it seems unlikely that a soluble gD vaccine alone will be useful as a vaccine for women and men. Additional HSV glycoproteins, peptide vaccines associated with heat shock proteins or with new adjuvants, or DNA vaccines are likely to be very safe, but it is unclear at present whether they will be sufficiently immunogenic. Safety is a primary concern when vaccinating healthy persons and therefore, in our opinion, a replication-defective vaccine or an inactivated virus vaccine would be appropriate candidates to test in clinical trials. If replication-defective and/or inactivated vaccines are ineffective, a live attenuated vaccine should be tested in clinical trials. Such a vaccine seems most likely to be effective, since it should elicit a broad immune response and a precedent exists with the live attenuated varicella vaccine. However, the safety of a live attenuated HSV vaccine will be of paramount importance.

\section{References}

Papers of special note have been highlighted as:

- of interest

•• of considerable interest

1. Looker KJ, Garnett GP, Schmid GP. An estimate of the global prevalence and incidence of herpes simplex virus type 2 infection. Bull World Health Organ. 2008; 86(10):805-812A. [PubMed: 18949218]

2. Fleming DT, McQuillan GM, Johnson RE, et al. Herpes simplex virus type 2 in the United States, 1976 to 1994. N Engl J Med. 1997; 337(16):1105-1111. [PubMed: 9329932]

3. Whitley RJ, Nahmias AJ, Soong SJ, Galasso GG, Fleming CL, Alford CA. Vidarabine therapy of neonatal herpes simplex virus infection. Pediatrics. 1980; 66(4):495-501. [PubMed: 7001331]

4. Kimberlin DW. Neonatal herpes simplex infection. Clin Microbiol Rev. 2004; 17(1):1-13. [PubMed: 14726453]

5. Siegal FP, Lopez C, Hammer GS, et al. Severe acquired immunodeficiency in male homosexuals, manifested by chronic perianal ulcerative herpes simplex lesions. N Engl J Med. 1981; 305(24): 1439-1444. [PubMed: 6272110] 
6. Basse G, Mengelle C, Kamar N, et al. Disseminated herpes simplex type-2 (HSV-2) infection after solid-organ transplantation. Infection. 2008; 36(1):62-64. [PubMed: 18165863]

7. Britton CB, Mesa-Tejada R, Fenoglio CM, Hays AP, Garvey GG, Miller JR. A new complication of AIDS: thoracic myelitis caused by herpes simplex virus. Neurology. 1985; 35(7):1071-1074. [PubMed: 2989730]

8. Corey L, Wald A, Celum CL, Quinn TC. The effects of herpes simplex virus-2 on HIV-1 acquisition and transmission: a review of two overlapping epidemics. J Acquir Immune Defic Syndr. 2004; 35(5):435-445. [PubMed: 15021308]

9. Freeman EE, Weiss HA, Glynn JR, Cross PL, Whitworth JA, Hayes RJ. Herpes simplex virus 2 infection increases HIV acquisition in men and women: systematic review and meta-analysis of longitudinal studies. AIDS. 2006; 20(1):73-83. [PubMed: 16327322]

10. Corey L, Wald A, Patel R, et al. Valacyclovir HSV Transmission Study Group. Once-daily valacyclovir to reduce the risk of transmission of genital herpes. N Engl J Med. 2004; 350(1):1120. [PubMed: 14702423]

11. LeBlanc RA, Pesnicak L, Godleski M, Straus SE. The comparative effects of famciclovir and valacyclovir on herpes simplex virus type 1 infection, latency, and reactivation in mice. J Infect Dis. 1999; 180(3):594-599. [PubMed: 10438344]

12. Sawtell NM, Thompson RL. Rapid in vivo reactivation of herpes simplex virus in latently infected murine ganglionic neurons after transient hyperthermia. J Virol. 1992; 66(4):2150-2156. [PubMed: 1312625]

13. Stanberry LR, Kern ER, Richards JT, Abbott TM, Overall JC Jr. Genital herpes in guinea pigs: pathogenesis of the primary infection and description of recurrent disease. J Infect Dis. 1982; 146(3):397-404. [PubMed: 6286797]

14. Stanberry LR, Kern ER, Richards JT, Overall JC Jr. Recurrent genital herpes simplex virus infection in guinea pigs. Intervirology. 1985; 24(4):226-231. [PubMed: 3000982]

15. Yim KC, Carroll CJ, Tuyama A, et al. The cotton rat provides a novel model to study genital herpes infection and to evaluate preventive strategies. J Virol. 2005; 79(23):14632-14639. [PubMed: 16282463]

16. Crostarosa F, Aravantinou M, Akpogheneta OJ, et al. A macaque model to study vaginal HSV-2/ immunodeficiency virus co-infection and the impact of HSV-2 on microbicide efficacy. PLoS ONE. 2009; 4(11):e8060. [PubMed: 20011586]

17. Melendez LV, España C, Hunt RD, Daniel MD, Garcia FG. Natural herpes simplex infection in the owl monkey (Aotus trivirgatus). Lab Anim Care. 1969; 19(1):38-45. [PubMed: 4304237]

18. Meignier B, Martin B, Whitley RJ, Roizman B. In vivo behavior of genetically engineered herpes simplex viruses R7017 and R7020. II Studies in immunocompetent and immunosuppressed owl monkeys (Aotus trivirgatus). J Infect Dis. 1990; 162(2):313-321. [PubMed: 2165104]

19. Ahn K, Meyer TH, Uebel S, et al. Molecular mechanism and species specificity of TAP inhibition by herpes simplex virus ICP47. EMBO J. 1996; 15(13):3247-3255. [PubMed: 8670825]

20. Johansson PJ, Myhre EB, Blomberg J. Specificity of Fc receptors induced by herpes simplex virus type 1: comparison of immunoglobulin G from different animal species. J Virol. 1985; 56(2):489494. [PubMed: 2997471]

21. Szpara ML, Parsons L, Enquist LW. Sequence variability in clinical and laboratory isolates of herpes simplex virus 1 reveals new mutations. J Virol. 2010; 84(10):5303-5313. [PubMed: 20219902]

22. Cohen GH, Dietzschold B, Ponce de Leon M, et al. Localization and synthesis of an antigenic determinant of herpes simplex virus glycoprotein $\mathrm{D}$ that stimulates the production of neutralizing antibody. J Virol. 1984; 49(1):102-108. [PubMed: 6197535]

23. Kohl S, Charlebois ED, Sigouroudinia M, et al. Limited antibody-dependent cellular cytotoxicity antibody response induced by a herpes simplex virus type 2 subunit vaccine. J Infect Dis. 2000; 181(1):335-339. [PubMed: 10608784]

24. Kim M, Taylor J, Sidney J, et al. Immunodominant epitopes in herpes simplex virus type 2 glycoprotein D are recognized by CD4 lymphocytes from both HSV-1 and HSV-2 seropositive subjects. J Immunol. 2008; 181(9):6604-6615. [PubMed: 18941251] 
25. Prober CG, Sullender WM, Yasukawa LL, Au DS, Yeager AS, Arvin AM. Low risk of herpes simplex virus infections in neonates exposed to the virus at the time of vaginal delivery to mothers with recurrent genital herpes simplex virus infections. N Engl J Med. 1987; 316(5):240-244. [PubMed: 3025727]

26. Sullender WM, Miller JL, Yasukawa LL, et al. Humoral and cell-mediated immunity in neonates with herpes simplex virus infection. J Infect Dis. 1987; 155(1):28-37. [PubMed: 3025306]

27. Bernstein DI, Aoki FY, Tyring SK, et al. GlaxoSmithKline Herpes Vaccine Study Group. Safety and immunogenicity of glycoprotein D-adjuvant genital herpes vaccine. Clin Infect Dis. 2005; 40(9):1271-1281. [PubMed: 15825029]

28••. Belshe RB, Leone PA, Bernstein DI, et al. Herpevac Trial for Women. Efficacy results of a trial of a herpes simplex vaccine. N Engl J Med. 2012; 366(1):34-43. Phase III trial of HSV-2 gD2 in aluminum hydroxide (alum)/3-O-deacylated-monophosphoryl lipid A (MPL) failed to protect against combined HSV-1 and -2 genital herpes, but had some activity against HSV-1 genital disease and infection. Antibody responses to HSV correlated with protection from HSV-1 infection. [PubMed: 22216840]

29. Cunningham AL, Turner RR, Miller AC, Para MF, Merigan TC. Evolution of recurrent herpes simplex lesions. An immunohistologic study. J Clin Invest. 1985; 75(1):226-233. [PubMed: 3880773]

30. Koelle DM, Posavad CM, Barnum GR, Johnson ML, Frank JM, Corey L. Clearance of HSV-2 from recurrent genital lesions correlates with infiltration of HSV-specific cytotoxic T lymphocytes. J Clin Invest. 1998; 101(7):1500-1508. [PubMed: 9525993]

31. Zhu J, Koelle DM, Cao J, et al. Virus-specific $\mathrm{CD}^{+} \mathrm{T}$ cells accumulate near sensory nerve endings in genital skin during subclinical HSV-2 reactivation. J Exp Med. 2007; 204(3):595-603. [PubMed: 17325200]

32. Hoshino Y, Pesnicak L, Cohen JI, Straus SE. Rates of reactivation of latent herpes simplex virus from mouse trigeminal ganglia ex vivo correlate directly with viral load and inversely with number of infiltrating CD8 ${ }^{+}$T cells. J Virol. 2007; 81(15):8157-8164. [PubMed: 17522198]

33. Simmons A, Tscharke DC. Anti-CD8 impairs clearance of herpes simplex virus from the nervous system: implications for the fate of virally infected neurons. J Exp Med. 1992; 175(5):1337-1344. [PubMed: 1314887]

34. Hosken N, McGowan P, Meier A, et al. Diversity of the $\mathrm{CD} 8^{+} \mathrm{T}$-cell response to herpes simplex virus type 2 proteins among persons with genital herpes. J Virol. 2006; 80(11):5509-5515. [PubMed: 16699031]

35. Laing KJ, Magaret AS, Mueller DE, et al. Diversity in CD8 $\left({ }^{+}\right) \mathrm{T}$ cell function and epitope breadth among persons with genital herpes. J Clin Immunol. 2010; 30(5):703-722. [PubMed: 20635156]

36. Koelle DM, Liu Z, McClurkan CL, et al. Immunodominance among herpes simplex virus-specific CD8 T cells expressing a tissue-specific homing receptor. Proc Natl Acad Sci USA. 2003; 100(22):12899-12904. [PubMed: 14566059]

37. Koelle DM, Chen HB, Gavin MA, Wald A, Kwok WW, Corey L. CD8 CTL from genital herpes simplex lesions: recognition of viral tegument and immediate early proteins and lysis of infected cutaneous cells. J Immunol. 2001; 166(6):4049-4058. [PubMed: 11238653]

38. Koelle DM, Frank JM, Johnson ML, Kwok WW. Recognition of herpes simplex virus type 2 tegument proteins by CD4 T cells infiltrating human genital herpes lesions. J Virol. 1998; 72(9): 7476-7483. [PubMed: 9696844]

39. Posavad CM, Remington M, Mueller DE, et al. Detailed characterization of $\mathrm{T}$ cell responses to herpes simplex virus-2 in immune seronegative persons. J Immunol. 2010; 184(6):3250-3259. [PubMed: 20164419]

40. Sainz B Jr, Halford WP. $a / \beta$ interferon and $\gamma$ interferon synergize to inhibit the replication of herpes simplex virus type 1. J Virol. 2002; 76(22):11541-11550. [PubMed: 12388715]

41. Leventon-Kriss S, Movshovitz M, Smetana Z, Shewach-Millet M, Doerner T, Gotlieb-Stematsky T. Sensitivity in vitro of herpes simplex virus isolates to human fibroblast interferon. Med Microbiol Immunol. 1987; 176(3):151-159. [PubMed: 3037288] 
42. Sancho-Shimizu V, Pérez de Diego R, Lorenzo L, et al. Herpes simplex encephalitis in children with autosomal recessive and dominant TRIF deficiency. J Clin Invest. 2011; 121(12):4889-4902. [PubMed: 22105173]

43. Dropulic LK, Cohen JI. Severe viral infections and primary immunodeficiencies. Clin Infect Dis. 2011; 53(9):897-909. [PubMed: 21960712]

44. Sakaoka H, Aomori T, Gouro T, Kumamoto Y. Demonstration of either endogenous recurrence or exogenous reinfection by restriction endonuclease cleavage analysis of herpes simplex virus from patients with recrudescent genital herpes. J Med Virol. 1995; 46(4):387-396. [PubMed: 7595418]

45. Roest RW, Maertzdorf J, Kant M, van der Meijden WI, Osterhaus AD, Verjans GM. High incidence of genotypic variance between sequential herpes simplex virus type 2 isolates from HIV-1-seropositive patients with recurrent genital herpes. J Infect Dis. 2006; 194(8):1115-1118. [PubMed: 16991086]

46. Kern AB, Schiff BL. Vaccine therapy in recurrent herpes simplex. Arch Dermatol. 1964; 89:844845. [PubMed: 14164972]

47. Kutinová L, Benda R, Kalos Z, et al. Placebo-controlled study with subunit herpes simplex virus vaccine in subjects suffering from frequent herpetic recurrences. Vaccine. 1988; 6(3):223-228. [PubMed: 2844031]

48. Mertz GJ, Ashley R, Burke RL, et al. Double-blind, placebo-controlled trial of a herpes simplex virus type 2 glycoprotein vaccine in persons at high risk for genital herpes infection. J Infect Dis. 1990; 161(4):653-660. [PubMed: 2181031]

49. Skinner GR, Turyk ME, Benson CA, et al. The efficacy and safety of Skinner herpes simplex vaccine towards modulation of herpes genitalis; report of a prospective double-blind placebocontrolled trial. Med Microbiol Immunol. 1997; 186(1):31-36. [PubMed: 9255764]

50. Corey L, Langenberg AG, Ashley R, et al. Recombinant glycoprotein vaccine for the prevention of genital HSV-2 infection: two randomized controlled trials. Chiron HSV Vaccine Study Group. JAMA. 1999; 282(4):331-340. [PubMed: 10432030]

51. Stanberry LR, Spruance SL, Cunningham AL, et al. GlaxoSmithKline Herpes Vaccine Efficacy Study Group. Glycoprotein-D-adjuvant vaccine to prevent genital herpes. N Engl J Med. 2002; 347(21):1652-1661. [PubMed: 12444179]

52. Meignier B, Longnecker R, Roizman B. In vivo behavior of genetically engineered herpes simplex viruses R7017 and R7020: construction and evaluation in rodents. J Infect Dis. 1988; 158(3):602614. [PubMed: 2842408]

53. Whitley RJ, Roizman B. Herpes simplex viruses: is a vaccine tenable? J Clin Invest. 2002; 110(2): 145-151. [PubMed: 12122103]

54••. Straus SE, Corey L, Burke RL, et al. Placebo-controlled trial of vaccination with recombinant glycoprotein $\mathrm{D}$ of herpes simplex virus type 2 for immunotherapy of genital herpes. Lancet. 1994; 343(8911):1460-1463. High-dose HSV-2 gD2 in alum reduced recurrence rates in persons with recurrent disease. Provides a proof of concept for a therapeutic HSV-2 vaccine. [PubMed: 7911177]

55. Straus SE, Wald A, Kost RG, et al. Immunotherapy of recurrent genital herpes with recombinant herpes simplex virus type 2 glycoproteins D and B: results of a placebo-controlled vaccine trial. J Infect Dis. 1997; 176(5):1129-1134. [PubMed: 9359709]

56. Casanova G, Cancela R, Alonzo L, et al. A double-blind study of the efficacy and safety of the ICP10deltaPK vaccine against recurrent genital HSV-2 infections. Cutis. 2002; 70(4):235-239. [PubMed: 12403316]

57. Wachsman M, Kulka M, Smith CC, Aurelian L. A growth and latency compromised herpes simplex virus type 2 mutant (ICP10deltaPK) has prophylactic and therapeutic protective activity in guinea pigs. Vaccine. 2001; 19(15-16):1879-1890. [PubMed: 11228357]

58. de Bruyn G, Vargas-Cortez M, Warren T, et al. A randomized controlled trial of a replication defective ( $\mathrm{gH}$ deletion) herpes simplex virus vaccine for the treatment of recurrent genital herpes among immunocompetent subjects. Vaccine. 2006; 24(7):914-920. [PubMed: 16213066]

59. Cattamanchi A, Posavad CM, Wald A, et al. Phase I study of a herpes simplex virus type 2 (HSV-2) DNA vaccine administered to healthy, HSV-2-seronegative adults by a needle-free injection system. Clin Vaccine Immunol. 2008; 15(11):1638-1643. [PubMed: 18784341] 
60•. Wald A, Koelle DM, Fife K, et al. Safety and immunogenicity of long HSV-2 peptides complexed with rhHsc70 in HSV-2 seropositive persons. Vaccine. 2011; 29(47):8520-8529. Heat-shock protein mixed with multiple long HSV-2 peptides induced HSV-2-specific CD4 and CD8 cell responses. Indicates that HSV-2-specific CD8 cells can be induced with a peptide vaccine. [PubMed: 21945262]

61. Srivastava P. Roles of heat-shock proteins in innate and adaptive immunity. Nat Rev Immunol. 2002; 2(3):185-194. [PubMed: 11913069]

62. Hook LM, Lubinski JM, Jiang M, Pangburn MK, Friedman HM. Herpes simplex virus type 1 and 2 glycoprotein $\mathrm{C}$ prevents complement-mediated neutralization induced by natural immunoglobulin M antibody. J Virol. 2006; 80(8):4038-4046. [PubMed: 16571820]

63•. Awasthi S, Lubinski JM, Shaw CE, et al. Immunization with a vaccine combining herpes simplex virus 2 (HSV-2) glycoprotein $\mathrm{C}(\mathrm{gC})$ and $\mathrm{gD}$ subunits improves the protection of dorsal root ganglia in mice and reduces the frequency of recurrent vaginal shedding of HSV-2 DNA in guinea pigs compared to immunization with gD alone. J Virol. 2011; 85(20):10472-10486. HSV-2 gC enhanced the efficacy of HSV-2 gD to protect guinea pigs from HSV-2 ganglionic infection and virus shedding. Suggests that blocking an immune evasion function of the virus can enhance vaccine efficacy. [PubMed: 21813597]

64- Morello CS, Levinson MS, Kraynyak KA, Spector DH. Immunization with herpes simplex virus 2 (HSV-2) genes plus inactivated HSV-2 is highly protective against acute and recurrent HSV-2 disease. J Virol. 2011; 85(7):3461-3472. Vaccination with formalin-inactivated HSV-2 in alum/ MPL adjuvant showed excellent protection in guinea pigs and suggests that inactivated virus in the appropriate adjuvant may be a useful vaccine platform. [PubMed: 21270160]

65. Da Costa X, Kramer MF, Zhu J, Brockman MA, Knipe DM. Construction, phenotypic analysis, and immunogenicity of a UL5/UL29 double deletion mutant of herpes simplex virus 2. J Virol. 2000; 74(17):7963-7971. [PubMed: 10933704]

66. Da Costa XJ, Jones CA, Knipe DM. Immunization against genital herpes with a vaccine virus that has defects in productive and latent infection. Proc Natl Acad Sci USA. 1999; 96(12):6994-6998. [PubMed: 10359827]

67. Hoshino Y, Dalai SK, Wang K, et al. Comparative efficacy and immunogenicity of replicationdefective, recombinant glycoprotein, and DNA vaccines for herpes simplex virus 2 infections in mice and guinea pigs. J Virol. 2005; 79(1):410-418. [PubMed: 15596834]

68. Hoshino Y, Pesnicak L, Dowdell KC, et al. Protection from herpes simplex virus (HSV)-2 infection with replication-defective HSV-2 or glycoprotein D2 vaccines in HSV-1-seropositive and HSV-1-seronegative guinea pigs. J Infect Dis. 2009; 200(7):1088-1095. HSV-2 dl-29 reduced acute and recurrent disease and shedding in HSV-1-seropositive or HSV-1-seronegative guinea pigs after challenge with HSV-2. Shows that a replication-defective vaccine can be protective regardless of prior HSV-1 infection. [PubMed: 19702506]

69. Hoshino Y, Pesnicak L, Dowdell KC, et al. Comparison of immunogenicity and protective efficacy of genital herpes vaccine candidates herpes simplex virus 2 d15-29 and d15-29-41L in mice and guinea pigs. Vaccine. 2008; 26(32):4034-4040. [PubMed: 18565628]

70. Lu Z, Brans R, Akhrameyeva NV, Murakami N, Xu X, Yao F. High-level expression of glycoprotein D by a dominant-negative HSV-1 virus augments its efficacy as a vaccine against HSV-1 infection. J Invest Dermatol. 2009; 129(5):1174-1184. [PubMed: 19005489]

71. Brans R, Akhrameyeva NV, Yao F. Prevention of genital herpes simplex virus type 1 and 2 disease in mice immunized with a $\mathrm{gD}$-expressing dominant-negative recombinant HSV-1. J Invest Dermatol. 2009; 129(10):2470-2479. [PubMed: 19357711]

72. Brans R, Yao F. Immunization with a dominant-negative recombinant herpes simplex virus (HSV) type 1 protects against HSV-2 genital disease in guinea pigs. BMC Microbiol. 2010; 10:163. [PubMed: 20525279]

73. Thebeau LG, Vagvala SP, Wong YM, Morrison LA. B7 costimulation molecules expressed from the herpes simplex virus 2 genome rescue immune induction in B7-deficient mice. J Virol. 2007; 81(22):12200-12209. [PubMed: 17804511]

74. Vagvala SP, Thebeau LG, Wilson SR, Morrison LA. Virus-encoded b7-2 costimulation molecules enhance the protective capacity of a replication-defective herpes simplex virus type 2 vaccine in immunocompetent mice. J Virol. 2009; 83(2):953-960. [PubMed: 18987142] 
75. Wang F, Zumbrun EE, Huang J, Si H, Makaroun L, Friedman HM. Herpes simplex virus type 2 glycoprotein $\mathrm{E}$ is required for efficient virus spread from epithelial cells to neurons and for targeting viral proteins from the neuron cell body into axons. Virology. 2010; 405(2):269-279. [PubMed: 20598729]

76•. Awasthi S, Zumbrun EE, Si H, et al. Live attenuated herpes simplex virus 2 glycoprotein E deletion mutant as a vaccine candidate defective in neuronal spread. J Virol. 2012; 86(8):45864598. HSV-2 deleted for gE reduced acute and recurrent disease and reduced shedding in guinea pig. The vaccine also reduced recurrences in previously infected animals. Shows that a live attenuated vaccine can be safe and effective in an animal model. [PubMed: 22318147]

77. Mossman KL, Saffran HA, Smiley JR. Herpes simplex virus ICP0 mutants are hypersensitive to interferon. J Virol. 2000; 74(4):2052-2056. [PubMed: 10644380]

78. Halford WP, Püschel R, Rakowski B. Herpes simplex virus 2 ICP0 mutant viruses are avirulent and immunogenic: implications for a genital herpes vaccine. PLoS ONE. 2010; 5(8):e12251. [PubMed: 20808928]

79. Halford WP, Püschel R, Gershburg E, Wilber A, Gershburg S, Rakowski B. A live-attenuated HSV-2 ICP0 virus elicits 10 to 100 times greater protection against genital herpes than a glycoprotein D subunit vaccine. PLoS ONE. 2011; 6(3):e17748. [PubMed: 21412438]

80. Manoj S, Jogger CR, Myscofski D, Yoon M, Spear PG. Mutations in herpes simplex virus glycoprotein D that prevent cell entry via nectins and alter cell tropism. Proc Natl Acad Sci USA. 2004; 101(34):12414-12421. [PubMed: 15273289]

81. Awasthi S, Lubinski JM, Eisenberg RJ, Cohen GH, Friedman HM. An HSV-1 gD mutant virus as an entry-impaired live virus vaccine. Vaccine. 2008; 26(9):1195-1203. [PubMed: 18243431]

82. Wang K, Kappel JD, Canders C, et al. An HSV-2 glycoprotein D mutant, generated by BAC mutagenesis, is severely impaired for infecting neuronal cells and only infects vero cells expressing exogenous HVEM. J Virol. 2012; 86(23):12891-12902. [PubMed: 22993162]

83. Bernstein HH, Rothstein EP, Watson BM, et al. Clinical survey of natural varicella compared with breakthrough varicella after immunization with live attenuated Oka/Merck varicella vaccine. Pediatrics. 1993; 92(6):833-837. [PubMed: 8233746]

84. Mark KE, Wald A, Magaret AS, et al. Rapidly cleared episodes of herpes simplex virus reactivation in immunocompetent adults. J Infect Dis. 2008; 198(8):1141-1149. [PubMed: 18783315]

85. Meier JL, Straus SE. Comparative biology of latent varicella-zoster virus and herpes simplex virus infections. J Infect Dis. 1992; 166(Suppl 1):S13-S23. [PubMed: 1320646]

86. Dudek T, Knipe DM. Replication-defective viruses as vaccines and vaccine vectors. Virology. 2006; 344(1):230-239. [PubMed: 16364753]

87. Roteli-Martins CM, Naud P, De Borba P, et al. Sustained immunogenicity and efficacy of the HPV-16/18 AS04-adjuvanted vaccine: up to 8.4 years of follow-up. Hum Vaccin Immunother. 2012; 8(3):390-397. [PubMed: 22327492]

88. Longet S, Schiller JT, Bobst M, Jichlinski P, Nardelli-Haefliger D. A murine genital-challenge model is a sensitive measure of protective antibodies against human papillomavirus infection. $\mathrm{J}$ Virol. 2011; 85(24):13253-13259. [PubMed: 21976653]

89. Kines RC, Thompson CD, Lowy DR, Schiller JT, Day PM. The initial steps leading to papillomavirus infection occur on the basement membrane prior to cell surface binding. Proc Natl Acad Sci USA. 2009; 106(48):20458-20463. [PubMed: 19920181]

\section{Website}

101. BioVex Initiates Phase 1 Clinical Trial With Its Genital Herpes Vaccine, ImmunoVEXHSV2. www.medicalnewstoday.com/releases/181424.php 


\section{Key issues}

- Animal studies suggest that neutralizing antibody responses are important for successful prophylactic vaccination. However, success of a vaccine in animals does not guarantee success in humans, as demonstrated by the recent failure of a recombinant $\mathrm{gD} 2$ vaccine to prevent HSV-2 infection or HSV-2 genital disease in humans. Vaccine development should focus on strategies that will elicit a broad immune response that recognizes a diverse set of viral antigens.

- Clinical studies suggest that virus-specific T-cell responses will be necessary for an effective therapeutic vaccine in humans.

- Continued study of the biology of HSV and of immunologic correlates of protection for control of HSV infection are needed for vaccine development. Potent immune responses at the site of infection (genital tract) will be important.

- Replication-defective or live attenuated vaccines that express a broad array of viral antigens and vaccine approaches that use novel molecular strategies, such as complexing multiple viral antigens to heat shock proteins, should be tested in addition to newer approaches using glycoprotein vaccines.

- HSV-2 vaccines that reduce primary disease and shedding are an important goal for an HSV-2 vaccine. While sterilizing immunity would be ideal, the observation that persons can become infected with more than one strain of HSV-2 suggests that this might not be achievable.

- In developed countries, HSV-1 infection is emerging as the most frequent cause of primary genital herpes in young women. Therefore, an effective genital herpes vaccine will need to protect against both HSV-2 and HSV-1. 
Table 1

Animal models used for herpes simplex virus-2 vaccine development.

\begin{tabular}{|lll|}
\hline Animal & Advantages & Disadvantages \\
\hline Mouse & Inexpensive & No spontaneous reactivation \\
& Immune reagents available & No spontaneous shedding \\
& Inbred strains, including HLA transgenics, available & Requires medroxyprogesterone for intravaginal infection \\
\hline \multirow{2}{*}{ Guinea pig } & Spontaneous reactivation and shedding & Limited immune reagents \\
\hline \multirow{2}{*}{ Cotton rat } & Spontaneous reactivation and shedding & Limited immune reagents \\
\hline \multirow{2}{*}{ Owl monkey } & Highly susceptible to HSV-2 infection & Animals die with very low titer inoculum \\
\hline
\end{tabular}




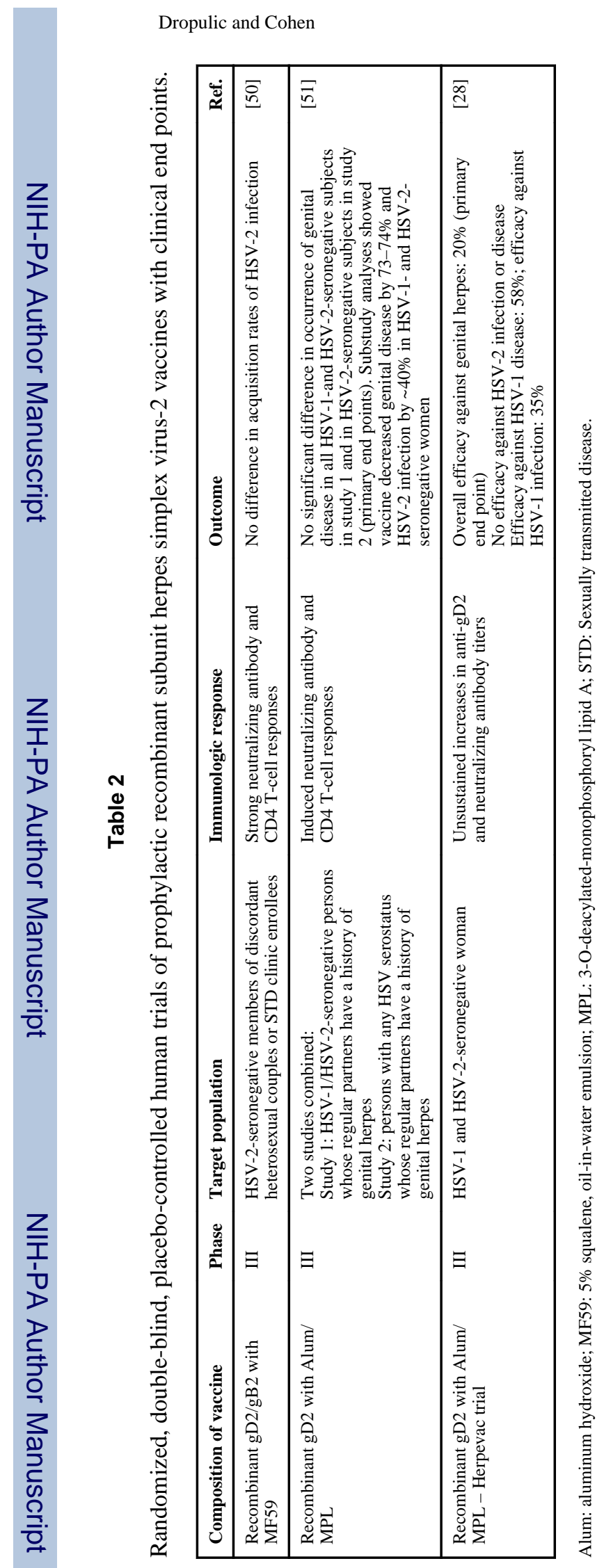

Page 19

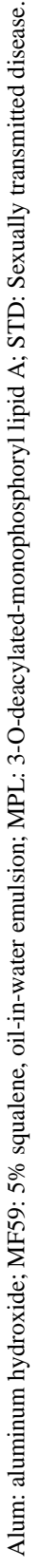

Expert Rev Vaccines. Author manuscript; available in PMC 2013 October 01. 


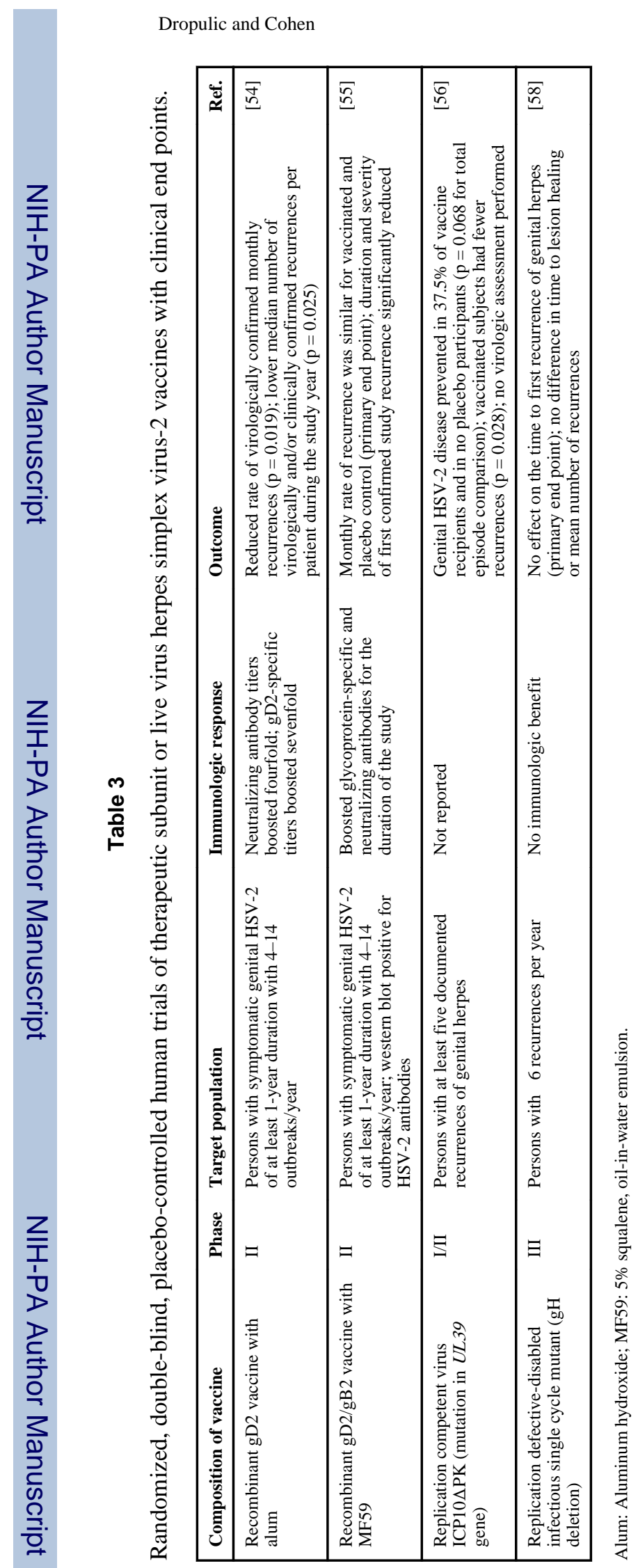

Expert Rev Vaccines. Author manuscript; available in PMC 2013 October 01. 
Table 4

Selected vaccines in preclinical studies.

\begin{tabular}{|c|c|c|c|}
\hline Vaccine & Property & Results in animals & Ref. \\
\hline Glycoprotein $\mathrm{gC}+\mathrm{gD}$ & $\begin{array}{l}\text { Blocks HSV- } 2 \text { immune evasion from } \\
\text { neutralization by complement }\end{array}$ & $\begin{array}{l}\text { Reduces latency and vaginal } \\
\text { shedding in mice and guinea } \\
\text { pigs, respectively }\end{array}$ & {$[63]$} \\
\hline $\begin{array}{l}\text { Inactivated virus in alum/MPL and HSV-2 } \\
\text { plasmids }\end{array}$ & Induces neutralizing antibody & $\begin{array}{l}\text { Reduces latency and recurrent } \\
\text { disease in guinea pigs }\end{array}$ & [64] \\
\hline Replication-defective (dl-5-29) & $\begin{array}{l}\text { Induces neutralizing antibody and } \\
\text { CD8 T-cell responses }\end{array}$ & $\begin{array}{l}\text { Reduces latency and mortality in } \\
\text { mice; reduces latency, acute and } \\
\text { recurrent disease in guinea pigs }\end{array}$ & [65-68] \\
\hline Replication-defective, CJ9-gD & $\begin{array}{l}\text { Overexpresses HSV-1 } \mathrm{gD} ; \mathrm{gD} \\
\text { expressed very early in infection }\end{array}$ & $\begin{array}{l}\text { Reduces shedding, genital } \\
\text { lesions, hindlimb paralysis and } \\
\text { death after intravaginal challenge } \\
\text { of mice with HSV-2 and reduces } \\
\text { shedding and recurrences in } \\
\text { guinea pigs }\end{array}$ & [70-72] \\
\hline Replication-defective B7-expressing, 5B-86 & Increased IFN- $\gamma$-expressing $\mathrm{T}$ cells & $\begin{array}{l}\text { Reduces viral replication in } \\
\text { vaginal mucosa, genital and } \\
\text { neurologic disease and mortality }\end{array}$ & {$[73,74]$} \\
\hline \multicolumn{4}{|l|}{ Live attenuated vaccines } \\
\hline HSV-2 gE-null mutant & $\begin{array}{l}\text { Defective anterograde transport and } \\
\text { cell-to-cell spread }\end{array}$ & $\begin{array}{l}\text { Reduces acute, recurrent disease } \\
\text { and shedding in guinea pigs; } \\
\text { reduces recurrent disease in } \\
\text { previously infected guinea pigs }\end{array}$ & {$[75,76]$} \\
\hline HSV-2 $0 \Delta \mathrm{NLS}$ & $\begin{array}{l}\text { Reduces activity of ICPO, an } \\
\text { interferon antagonist }\end{array}$ & $\begin{array}{l}\text { Reduces vaginal shedding and } \\
\text { mortality after intravaginal } \\
\text { challenge with HSV-2 compared } \\
\text { with gD in alum/MPL }\end{array}$ & {$[77,79]$} \\
\hline HSV-2 with mutations in $\mathrm{gD}$ & $\begin{array}{l}\text { Little or no infection of cells } \\
\text { expressing nectin- } 1 \text { in the absence of } \\
\text { herpes virus entry mediator - an HSV } \\
\text { receptor }\end{array}$ & $\begin{array}{l}\text { Protects mice from lethal } \\
\text { infection }\end{array}$ & $\begin{array}{r}\text { [82] [Wang et } \\
a l ., \\
\text { Unpublished } \\
\text { Data] }\end{array}$ \\
\hline
\end{tabular}

Alum: Aluminum hydroxide; MPL: 3-O-deacylated-monophosphoryl lipid A. 